\title{
Na distância da vítima: moralidade sobrevivente e a produção televisiva do indivíduo empreendedor de si
}

\section{Leandro Rodrigues Lage}

Universidade Federal do Pará, Programa de Pós-Graduação em Comunicação, Cultura e Amazônia, Belém, PA, Brasil

ORCID: https://orcid.org/0000-0002-6814-9640

Paulo Roberto Gibaldi Vaz

Universidade Federal do Rio de Janeiro, Programa de Pós-Graduação em Comunicação e Cultura, Rio de Janeiro, RJ, Brasil

ORCID: https://orcid.org/0000-0002-8776-2715

\section{Resumo}

$\mathrm{O}$ artigo analisa, em reality shows de sobrevivência, indícios de uma transformação cultural e moral do que se entende e se legitima como vítima, sofredor e como sobrevivência na contemporaneidade. A partir da observação do programa Largados e Pelados, do Discovery Channel, argumenta-se que essas produções televisivas investem narrativa e esteticamente tanto na espetacularização do sofrimento, quanto na produção cosmética do sobrevivente. Desse modo, a figura do sobrevivente passa a fazer parte de um tipo de pedagogia e de racionalidade orientados por uma lógica neoliberal de produção de indivíduos empreendedores de si. Esses reality shows atuam, portanto, como dispositivos produtores de modos de subjetivação associados ao heroísmo prodigioso e moralmente legítimo do sobrevivente, cuja imagem em negativo é a da vítima incapaz de superar os infortúnios com resiliência.

\section{Palavras-chave}

Moralidade. Sofrimento. Sobrevivência. Televisão. Vítima. 


\section{Introdução}

Após duas décadas de explosões de audiência dos reality shows em todo o mundo, parece ter desacelerado o interesse acadêmico por essas produções, seja pela ausência de novidades desse nicho criativo, seja pelo próprio desgaste dos programas, que anunciam continuamente suas últimas edições. Por outro lado, é preciso reconhecer, em primeiro lugar, que a chamada reality TV não é exatamente um fenômeno passageiro. E que ainda há muito a ser dito sobre essas produções e a natureza de seu vínculo com as práticas e os valores culturais contemporâneos: da saúde à alimentação, passando também pelas doenças e pelas práticas de cuidado de si; da sexualidade aos diversos modos de vida, incluindo-se as relações afetivas, a convivência e a privacidade; do consumo às lógicas competitivas e de mercado, tais como a moda, o empreendedorismo e os esportes; entre tantos outros.

Pode-se dizer que, além do fenômeno Big Brother, lançado em 1999, Survivor, de 2000, lançado pela Rede Globo no Brasil como No Limite, foi um dos grandes sucessos do gênero, inaugurando uma enorme diversidade dos chamados reality shows de sobrevivência. Na esteira de Survivor, um programa em particular despontou, desde 2013, no Discovery Channel, como um dos líderes de audiência da TV por assinatura: Largados e Pelados (Naked and Afraid) é, na verdade, uma entre outras tantas produções com esse perfil que ocupam, na última década, parte significativa da programação de canais de TV a cabo. Particularidades à parte, as características gerais dessas produções são bastante semelhantes: elas se passam em ambientes hostis, com ameaças constantes à saúde dos participantes, que, por sua vez, submetem-se voluntariamente a condições precárias de sobrevivência.

Trata-se, segundo Nayar (2009), de um amplo conjunto de produções que alimentam uma cultura visual do sofrimento e das cicatrizes, nas quais o corpo e a dor desses sujeitos são submetidos de bom grado ao risco constante. De maneira geral, programas televisivos de sobrevivência como Largados e Pelados constroem uma espécie de narrativa de aventura e de heroísmo na qual, diante das situações extremas de sofrimento e vulnerabilidade, seus participantes se tornam sobreviventes heroicos - quando não falham e/ou desistem. Essas produções televisivas são, para nós, sintomáticas daquilo que Rechtman e Fassin (2007) indicaram como uma ampla transformação cultural e moral do que se entende e se legitima como sofredor e como sobrevivente em nossos tempos. Historicamente vinculada às experiências da guerra, da doença, da violência, das catástrofes, a figura do sobrevivente 
parece estar, em nosso século, ligada à cultura do risco e aos desafios da vida contemporânea, emulados pelos reality shows.

Em trabalho anterior, argumentamos, por um lado, que produções televisivas como Largados e Pelados exploram não apenas o sofrimento e a subjugação de certos indivíduos, mas, sobretudo, sua capacidade de resistência, sua inventividade, sua vitalidade criativa e astuciosa (LAGE, 2018). Por outro lado, também já mostramos de que forma certas narrativas de sofrimento ensaiam um novo modo de produção da subjetividade contemporânea, ancorado sobretudo na figura de uma vítima heroica, capaz de sofrer, enfrentar suas provações com resiliência e superá-las, ocupando um lugar moralmente desejável de vítima (re)ativa e, no limite, célebre (VAZ, 2014). Referimo-nos, portanto, a formas de produção audiovisual biopolítica, ancoradas ética e esteticamente nas potências da vida que irrompem no centro das formas de dessubjetivação, mas também na definição de "bons" modos de sofrer e do sentido do sofrimento, isto é, de um modelo de conduta frente a dificuldades, riscos, desafios e privações que enfrentamos na contemporaneidade (FELDMAN, 2008).

Nosso argumento busca avançar sobre essas constatações, percebendo, a partir desses reality shows, indícios fortes de uma inversão histórica do estatuto moral do sobrevivente: no século passado, sobreviver às grandes catástrofes e guerras implicava sentimentos de culpa e vergonha, justamente porque a sobrevivência parecia depender da adoção de condutas moralmente ambíguas, como a subserviência e conivência com o agressor totalitário; em nossa época, ser sobrevivente (de fato ou apenas incorporar publicamente essa figura em programas de TV) parece depor moralmente a favor do sujeito, pois denota aptidão física e emocional, habilidade social e capacidade de resistência. A sobrevivência ensinada nesses programas foi transformada em sinônimo de força produtora e a própria figura do sobrevivente passa a fazer parte de um tipo de pedagogia e de racionalidade ancoradas na organização de saberes, nas relações de poder e no investimento em técnicas de si, orientados por uma lógica neoliberal de produção de indivíduos empreendedores de si.

Assim, nossa suspeita passa pela percepção de que a televisão atua como "dispositivo pedagógico" (FISCHER, 2002), ou melhor, como dispositivo produtor de modos de subjetivação, regulador de condutas, criador de campos de possibilidade, de ação e de realização dos sujeitos, orientando a nós, espectadores, a superar a antiga ambiguidade 
moral subjacente à sobrevivência em favor do heroísmo prodigioso da vítima voluntária e, sobretudo, voluntariosa. Essa linha argumentativa nos levará a duas constatações críticas: em primeiro lugar, à compreensão de que a contraface dessa pedagogia do sujeito neoliberal é, precisamente, uma imagem em negativo da vítima que não se enquadra nesse heroísmo, do desistente, do incapaz, do frágil, do que não necessariamente constitui-se como sobrevivente; em segundo lugar, ao entendimento de que a pedagogia da sobrevivência a qualquer custo é, também, uma pedagogia do sofrimento: a sobrevivência é, ao fim e ao cabo, ensinada como o único modo bom e legítimo de sofrer.

\section{Sobrevivência como espetáculo do sofrimento}

“Um homem e uma mulher, sós por 21 dias, sem comida, sem roupas, sem água. Teriam eles as habilidades e a vontade para superar o mais primitivo desafio de sobrevivência que eles jamais imaginaram, nus e amedrontados?" Após essa chamada de abertura, segue-se quase uma hora de programa, narrado desde a preparação dos participantes para a sofrida jornada em uma região florestal, pantanosa ou desértica mundo afora, até o reencontro com os familiares, mais de três semanas após a partida. Esse é, em linhas gerais, o enredo de Largados e Pelados, exemplo daquilo que se convencionou chamar de reality show de sobrevivência. A dimensão de sobrevivência se insinua no trabalho que essas narrativas têm de exibir imagens e relatos de sofrimento, centrados na figura do sobrevivente ou em experiências de sobrevivência em situações e ambientes específicos.

A lista de programas é extensa: No Limite (Survivor), Largados e Pelados (Naked and Afraid e spin-offs), Desafio em dose dupla (Dual survival; Masters of survival), Survivorman, $\grave{A}$ prova de tudo (Men vs. Wild), entre muitos outros. Os programas são exibidos, majoritariamente, por canais da rede Discovery, mas também pelo National Geographic, Animal Planet e History Channel. Essas produções possuem características mais ou menos específicas: são estreladas por apresentadores fixos, em geral especialistas em técnicas de sobrevivência primitiva e/ou ex-militares, por celebridades e/ou por pessoas comuns; são ou foram exibidos por emissoras de TV aberta ou por canais de TV por assinatura; possuem roteiros determinados, com provas e desafios estabelecidos previamente pela produção, ou exploram mais abertamente as possibilidades dos ambientes e situações vividos - como é o caso de Largados e Pelados. Todos eles, sem exceção, possuem um forte componente pedagógico associado ao imperativo de ensinar aos espectadores "técnicas primitivas e 
estratégias de sobrevivência" nas mais extremas condições. 0 tom pedagógico acompanha o enredo marcado por pessoas em circunstâncias extenuantes.

Porém, ao falarmos especificamente de reality shows de sobrevivência tais como Largados e Pelados, referimo-nos a uma modalidade específica de mediação e espetacularização do sofrimento: trata-se de um sofrimento voluntário, ao mesmo tempo real e fabricado (NAYAR, 2009). Ou, para sermos mais exatos, de um sofrimento fabricado para ser real. No centro dessas narrativas televisivas está a sobrevivência como experiência física, psíquica e, acima de tudo, mediada. E também a ambiguidade da figura do sobrevivente: ora como uma espécie de categoria sociocultural relacionada às experiências de sofrimento e ao imaginário contemporâneo do risco, ora como um sujeito individualizado, portador de um rosto, um corpo e uma fala que são tornados visíveis como parte de estratégias e apelos afetivos.

Diferentemente de Survivor, tanto Largados e Pelados quanto o spin-off da série, Largados e Pelados: A Tribo (Naked and Afraid XL), com 12 participantes e 40 dias de desafio, não possuem uma bateria de provas que medem "objetivamente" o desempenho dos desafiantes, tampouco se caracterizam como uma competição. A única "prova" é resistir ao ambiente, aos animais e às privações, preferencialmente adotando uma postura colaborativa na convivência com o parceiro ou os parceiros, no caso de $A$ Tribo. Aos participantes é dado um mapa com os locais de chegada e de resgate, que, em geral, ficam a uma distância de poucos quilômetros um do outro. Em Largados e Pelados, eles também podem levar para o desafio um item de sobrevivência de sua escolha. Os itens, em geral, são facões, panelas, iniciadores de fogo, anzóis, etc. Toda a narrativa se passa como se o que ocorresse entre o primeiro e o último dia de desafio fosse inteiramente definido pelos participantes: o que comem, onde dormem, o que fazem, onde montam acampamento, como fazem fogo.

Ao analisar a produção do conceito de sobrevivente em âmbitos discursivos específicos, tais como o Holocausto, a psicoterapia, o feminismo, os reality shows e os discursos sobre saúde, Orgad (2009) argumenta que a figura do sobrevivente constitui, na verdade, uma formação discursiva abrangente, histórica e descontínua. Para a autora, essa formação discursiva possui três características centrais: em primeiro lugar, o sobrevivente é um modo de ser que as pessoas são encorajadas a assumir. Isto é, não se trata de uma identidade fixa e permanente, mas de algo que se deve alcançar: tornar-se sobrevivente. Em segundo lugar, a imagem do sobrevivente representa força individual, bravura, 
autossuficiência e determinação. E, por fim, a sobrevivência deve transcender a experiência individual do trauma ou do sofrimento e, necessariamente, receber reconhecimento público.

0 argumento de Orgad (2009) abre a possibilidade de construção de uma chave compreensiva para o modo como determinadas narrativas televisivas produzem formas de sobrevivência, elaboram modelos de sobreviventes, ao mesmo tempo em que se valem dessa categoria sociocultural histórica para explorar certas dimensões do sofrimento especialmente aquela relacionada à resistência e à resiliência. 0 sofrimento, nesse sentido, está associado a uma forma de pedagogia, de saber e de dispositivos que operam como produtores de subjetivação, como reguladores de formas de gestão de si. Nesses programas, como veremos adiante, não basta chegar ao final do desafio sofrendo passivamente os revezes. É preciso seguir um roteiro de resiliência, sendo proativo, criativo, autêntico, paciente, estratégico e colaborativo, além de mostrar domínio das técnicas de sobrevivência, tais como a montagem de abrigos, a habilidade de encontrar ou produzir água potável e a sagacidade de caçar, pescar ou achar alimentos na natureza.

\section{Da naturalização do infortúnio à cosmética do sobrevivente na TV}

Há, nos realitys de sobrevivência, pelo menos dois mecanismos estéticos e narrativos utilizados na figuração televisual dos sobreviventes por esses programas: a espetacularização do sofrimento e a produção cosmética da vítima. No caso específico de Largados e Pelados, a espetacularização está vinculada, sobretudo, à nudez dos participantes, à exibição da degradação física e à criação de uma atmosfera de risco permanente. Já a recriação cosmética da vítima está ligada ao acompanhamento do declínio físico dos desafiantes, com ênfase em sua constante convocação a depor, a mostrar as marcas do sofrimento encarnado: as picadas de mosquitos e outros animais, as feridas abertas e cicatrizes, a perda significativa de massa corporal, a falta de higiene adequada, entre outros indícios que fazem dos participantes vítimas apresentáveis como tais, instadas a prestar depoimentos sobre a própria condição voluntária de sofrimento.

Nos primeiros minutos de todos os episódios de Largados e Pelados, os participantes são apresentados em seu check-in: estão em suas cidades, vestidos, acompanhados de familiares, e falam de si, do seu estilo de vida e de suas habilidades de sobrevivência. Muitas vezes filmam a si próprios ou aparecem em imagens de arquivo fazendo fogo, montando abrigos ou produzindo armas primitivas. Logo em seguida, os desafiantes são transportados 
no tempo e no espaço para uma das locações do programa, que já gravou episódios em países de todos os continentes do mundo, incluindo-se o Brasil. Depois de serem deixados nos locais pela equipe do programa, despem-se completamente e seguem natureza adentro. Nas cenas seguintes, ambos os participantes se encontram pela primeira vez, conforme as figuras 1 e 2 .

Figura 1 - Frame do primeiro episódio da segunda temporada de Largados e Pelados, quando os participantes Laura Zerra e EJ Snyder se cumprimentam.

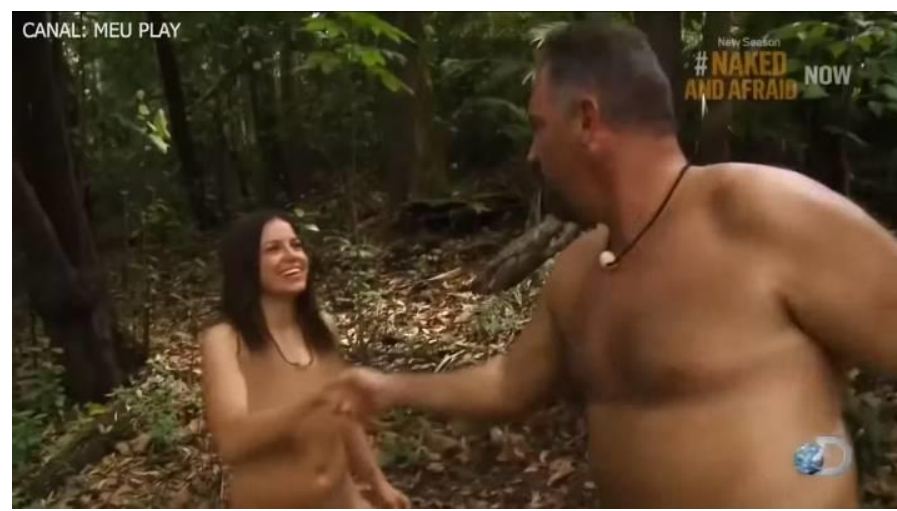

Fonte: MAN (2014).

Figura 2 - Frame do primeiro episódio da segunda temporada de Largados e Pelados. Cumprimento de Laura Zerra e EJ Snyder em plano aberto.

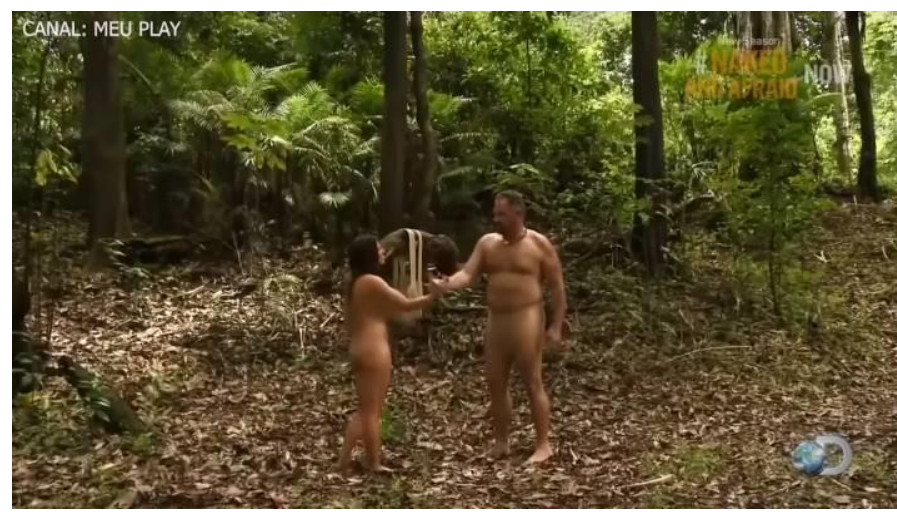

Fonte: MAN (2014).

A nudez que dá nome ao reality define esteticamente o programa, mas não apenas no sentido erótico. Em vez de ser um indício exclusivo das formas de regulação dos desejos de ver mais, de ver corpos sexualmente desnudados, de ver através do borrão que recobre as partes íntimas dos homens e mulheres, com raros momentos de exposição, a nudez é, talvez, um dos principais requintes de crueldade do programa. Trata-se de uma estratégia de acirramento das experiências de sofrimento e da vulnerabilidade dos indivíduos. Sem 
roupas, além de estarem sujeitos ao olhar do outro e da câmera, os participantes ficam sujeitos à ação do clima e de animais, ao desconforto físico e psicológico, a acidentes etc.

O sofrimento explorado por Largados e Pelados corresponde em muitos aspectos aos sofrimentos vividos pelos participantes de outros reality shows. Ao analisar o Hipertensão, adaptação brasileira do programa estadunidense Fear factor, Viana (2012) define com precisão a natureza dessa espetacularização do sofrimento: “A dor perpetrada e exposta por esse programa [..] mostra outra relação de nossa sociedade com o sofrimento que não a de sua ocultação ou de seu controle pela via da medicalização e da psiquiatria. É um sofrimento que chega a ser exaltado, um sofrimento digno" (VIANA, 2012, p. 151-152).

Não há sobreviventes legítimos sem que tenham seu sofrimento registrado nos mínimos detalhes. Nada mais é obsceno: a vulnerabilidade, o desespero, a fome, a dor são exibidos durante toda a duração do programa. 0 sofrimento é explorado em seus diversos matizes: é filmado e registrado, é vigiado e flagrado, é controlado e roteirizado, é narrado e testemunhado. Até a calmaria, quando mostrada em Largados e Pelados, é sob a forma do cansaço e do tédio, do desconforto ou da estafa, e até mesmo da inércia de certos participantes que se recusam a adotar uma postura proativa, como o programa preconiza.

$\mathrm{Na}$ oitava edição da primeira temporada, exibida originalmente em 2013 nos Estados Unidos e em 2015 no Brasil, os participantes Cassie De Pecol, Forrest Galante, Manu Toigo e Russell Sage são levados à costa do Panamá. Trata-se de uma edição especial, com quatro e não dois participantes. São dois casais que, no décimo dia de desafio, encontram-se e passam os últimos 11 dias juntos. Logo nas imagens de abertura - conforme as figuras $3 \mathrm{e}$ 4 - daquela edição especial do programa, intitulada Duplo perigo (Double jeopardy), a participante Manu Toigo é mostrada de pé, segurando raízes de uma árvore e gemendo de dor. No plano seguinte, está deitada na cama de um hospital, agonizando de dor e recebendo medicamentos intravenosos. Excessivamente magra e ativa, Manu é a participante que mais sofre com a privação de alimentos. Logo começa a apresentar sintomas de estafa e desnutrição. A única refeição substanciosa mostrada naquela edição é feita de caramujos recolhidos na praia e assados pelos participantes. 
Figura 3 - Frame da oitava edição da primeira temporada de Largados e Pelados. Participante Manu Toigo sofre pela falta de alimentação.

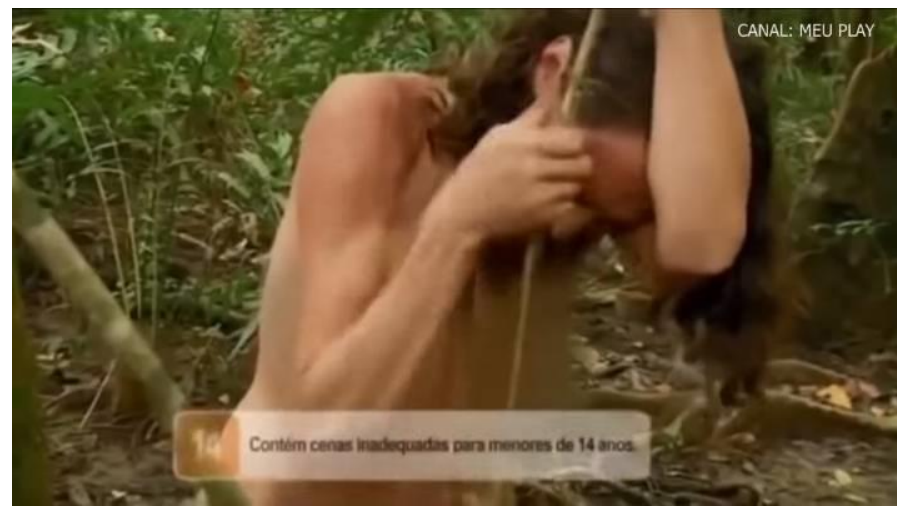

Fonte: SPECIAL (2013).

Figura 4 - Frame da oitava edição da primeira temporada de Largados e Pelados. Participante Manu Toigo internada com dengue hemorrágica.

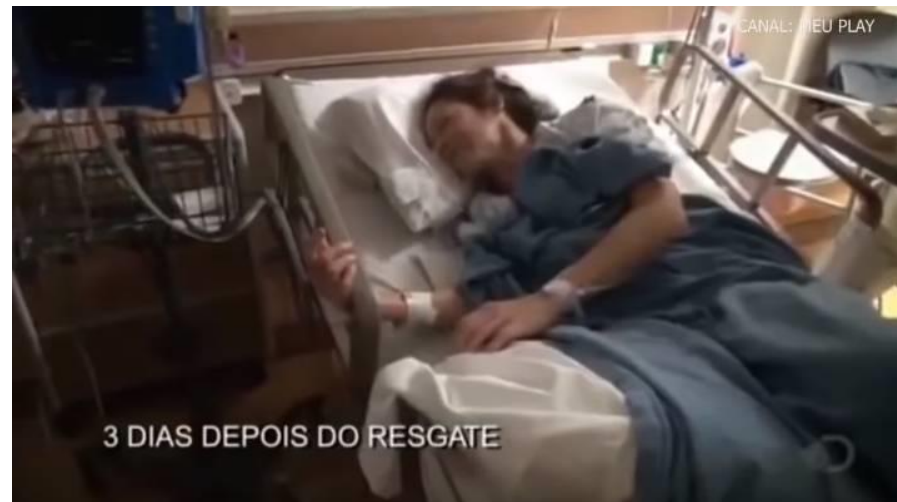

Fonte: SPECIAL (2013).

No 17ํ dia de desafio, sem ingerir nenhum tipo de alimento havia três dias, o grupo reduz drasticamente o ritmo de atividades. Manu Toigo, no entanto, insiste em recolher um tronco de bambu para construir a jangada que os levará até o ponto de resgate estabelecido pela produção do programa. Ao fazê-lo sob uma forte chuva e com a ameaça da maré alta, deixa o tronco cair sobre si e se machuca. Como o machucado não é grave, a desafiante não chega a ser retirada do programa, o que é comum entre os participantes, que com frequência se queimam nas fogueiras, sofrem quedas, cortes profundos, picadas de animais e adquirem alguma infecção. Ao final daquela edição, após serem retirados do local do desafio de helicóptero, a produção exibe as imagens da participante no hospital. Manu Toigo foi diagnosticada com dengue hemorrágica. "Ela ficou internada por duas semanas sentindo dores agonizantes devido à doença", diz o apresentador, em voz off. 
É esse tipo de investimento ostensivo na dor dos participantes que nos autoriza a inferir que esses reality shows de sobrevivência são, em sua maioria, responsáveis não apenas pela espetacularização do sofrimento, mas principalmente pela naturalização do infortúnio como espetáculo. 0 sofrimento é o fim e o meio dessas narrativas.

Em Largados e Pelados, cada participante recebe uma câmera individual, a qual deve ser utilizada diariamente para os depoimentos pessoais de cada desafiante sobre sua própria via crucis. As câmeras pessoais servem como uma espécie de confessionário, no qual, diferentemente das imagens registradas pela equipe técnica do programa, os participantes escolhem quando, onde e como filmarão a si próprios, produzindo a si mesmos como vítimas e sobreviventes. Ao final do programa, a narrativa é interrompida com gráficos comparativos medindo a perda de peso dos desafiantes, construídos com imagens do início e do fim do período de três semanas. As fotografias do início sempre trazem enquadramentos favoráveis aos participantes, mostrados em atividades enérgicas, bem nutridos. Já as do final investem naquilo que Bruckner (1996) chamou de "cosmética da vítima", convertida em cosmética do sobrevivente, meticulosamente produzido para parecer enquanto tal, depauperado, esquálido, abatido, em estado quase doentio, mas ainda assim vivo.

\section{Da vergonha ao heroísmo: a moralidade do sobrevivente}

Nesses reality shows, a sobrevivência, a despeito de ser sentida na carne, também é tratada como questão "mental", quase como um mantra motivacional. A regra é válida tanto para os diversos apresentadores-especialistas em sobrevivência, quanto para os desafiantes ordinários de Largados e Pelados - ainda que muitos deles sejam anunciados como "sobrevivencialistas". 0 credo é repetido recorrentemente: para sobreviver, não bastam a força, a destreza, a coragem. É preciso ter "resistência mental". Daí porque, a certa altura do desafio, quando confrontados com situações-limite, tais como a falta de água, de alimentos ou até mesmo o mal-estar físico, muitos dos participantes deixam o programa, enquanto outros perseveram diante do sofrimento psíquico, "viram a mesa" e dão ensejo a uma narrativa de superação, celebrada pelo próprio enredo da narrativa. Para Orgad (2009), essas narrativas reforçam a ideia de que alguém pode superar o infortúnio simplesmente adotando uma "psiquê de sobrevivente". 
O pressuposto de que a sobrevivência está ligada a dilemas morais e de que depende de condições emocionais também define narrativamente o programa Largados e Pelados. Na oitava edição da primeira temporada, a maior parte do episódio orbita em torno da participação discreta e pouco colaborativa de Cassie De Pecol, que se apresenta como ativista e sobrevivencialista, mas logo demonstra pouco conhecimento sobre como enfrentar a selva panamenha, o que a coloca em conflito com os parceiros.

Na maioria das vezes, os participantes do reality show deixam o programa por vontade própria, alegando não terem mais condições mentais para continuar. Em alguns episódios, a saída precoce de um participante é compensada pela entrada de um substituto. Em outros casos, o segundo participante resiste por pouco tempo e também escolhe sair. Mas os casos mais celebrados são aqueles em que um participante vence o desafio a despeito de mais esse obstáculo: ficar "sozinho". Esse foi o caso da participante Kim Kelly, do primeiro episódio da quinta temporada de Largados e Pelados, gravado também no Panamá. Diante das dificuldades impostas pela floresta panamenha, o parceiro de Kim desiste e ela segue sozinha por duas semanas, até o fim dos 21 dias, conforme as figuras 5 e 6 .

Figura 5 - Frame do primeiro episódio da quinta temporada de Largados e Pelados. Participante Kim Kelly relata dificuldades no desafio.

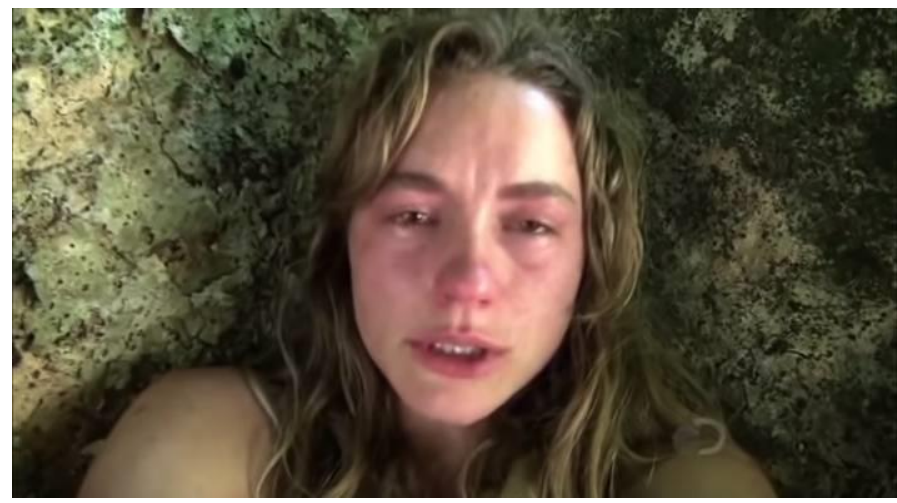

Fonte: FORSAKEN (2015). 
Figura 6 - Frame do primeiro episódio da quinta temporada de Largados e Pelados. Participante Kim Kelly comemora a conclusão do desafio.

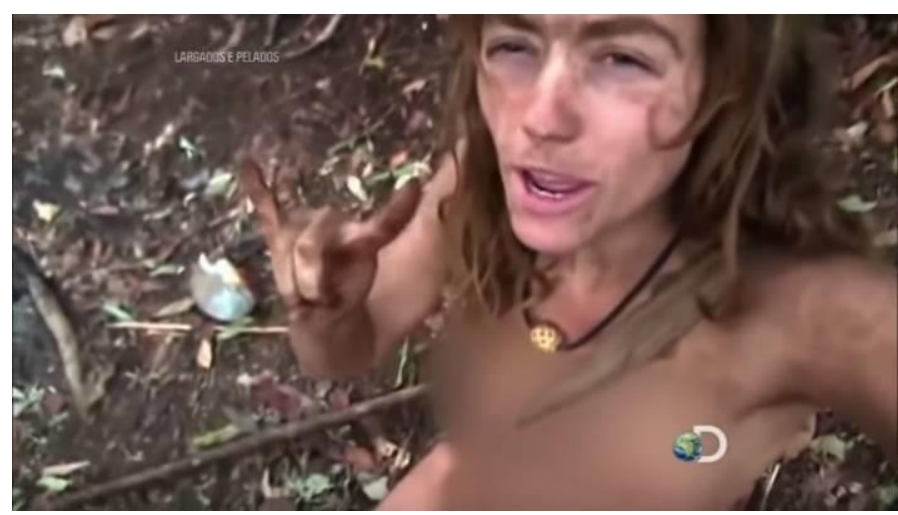

Fonte: FORSAKEN, 2015.

Kim Kelly é o símbolo exato da figura do sobrevivente que o programa celebra: aparentemente frágil, mas resiliente, equilibrado, autossuficiente, persistente, capaz de superar os obstáculos mais inesperados, oferecidos pelo ambiente ou pela própria dinâmica da convivência. Ela superou inclusive o machismo do ex-companheiro de desafio. Já Cassie De Pecol é a imagem em negativo desse sobrevivente. Trata-se de uma vítima passiva, de uma sobrevivente cuja legitimidade é ameaçada pela inabilidade para trabalhar em grupo, pela incapacidade de submeter-se com bravura às dificuldades impostas pelo desafio, escolhendo apenas economizar energias e "aguardar" o tempo passar. Após reiterados confrontos com os colegas, a própria Cassie chega a admitir vergonha de si mesma para sua câmera individual: "Talvez eu não saiba jogar em time, talvez eu não tenha ética para trabalhar em grupo. Eu tive essa oportunidade incrível e eu tô sentindo que eu estraguei tudo", diz a participante.

É nesse sentido que identificamos, nos programas televisivos reunidos sob a rubrica dos reality shows de sobrevivência, indícios marcantes daquilo que Rechtman e Fassin (2007) chamaram de economia moral do trauma: se, de certa forma, todos somos sofredores, são necessários qualificadores morais para legitimar uns sofredores mais do que outros. A diferença aqui é, no entanto, um relativo afastamento em relação ao nexo habitual entre trauma e evento catastrófico. Com isso, não se quer dizer que a legitimidade daqueles que passaram por alguma provação e a superaram prescinde das experiências traumáticas, como se o próprio trauma perdesse completamente seu valor moral na compreensão dos problemas sociais. 0 que se observa é, na verdade, uma flexibilização das normas morais a partir das quais aprendemos a legitimar e nos compadecer do sofrimento alheio, a admirar e 
nos inspirar no heroísmo dos sobreviventes - ainda que não sejam remanescentes de um genocídio, de uma catástrofe natural ou de experiências de violação, mas, sim, participantes voluntários de um show televisivo.

É certo que não há um parâmetro comparativo ou simetria razoável entre a experiência dos campos de concentração e os experimentos dos reality shows. A questão, no entanto, é outra. Trata-se de constatar o aspecto elementar de uma transformação cultural na forma como apreendemos não apenas o sofrimento alheio, mas a capacidade que os sujeitos têm de resistir ao infortúnio. 0 episódio dos campos mostra um momento histórico no qual a sobrevivência estava, ainda, desvinculada de uma expectativa moral determinante de resistência ativa, separada da resiliência como imperativo. A inversão histórica aponta para uma passagem da ambiguidade moral do sobrevivente ao heroísmo de quem resiste; a um abandono da culpa e da vergonha em favor do orgulho da superação. A vergonha, em nossos tempos, está vinculada à falha, ao fracasso, à incapacidade de resistir e passar no teste de sobrevivência. Em contrapartida, o heroísmo não remete, exatamente, a um grande feito, conquista ou vitória.

Nos modelos de sobreviventes fornecidos por programas como Largados e Pelados, Kim Kelly e Cassie De Pecol são exemplos opostos. Enquanto a primeira goza de legitimidade moral ao demonstrar aptidão física e emocional, modo de agir estratégico, espírito colaborativo e capacidade de resistência, a segunda ilustra bem a contraface dessa naturalização e legitimação da figura do sobrevivente heroico: a vítima, associada a uma condição passiva, dependente e frágil, quase que culpada pela ausência das desejáveis competências para gestão de si.

Qual seria, então, a consequência entre esse modelo de heroísmo forjado por programas de sobrevivência com a sociedade contemporânea? Para Orgad (2009), a construção do sobrevivente como imagem de um modo de ser que outros são encorajados a admirar e a adotar produz outras figuras como ilegítimas e menos desejáveis, como a da vítima "passiva". Essa imagem do sobrevivente capaz, "empoderado", autossuficiente e responsável por si mesmo automaticamente cria uma imagem em negativo do sobrevivente incapaz, fraco e dependente. "A vítima, por contraste, carece de responsabilidade própria; a vítima depende da sociedade e, portanto, convida a comunidade a prestar apoio. Mas esse chamado, se ouvido, é visto como sinal de fraqueza e dependência, para ser ridicularizado em vez de reconhecido" (ORGAD, 2009, p. 151, tradução nossa). 
Esses programas acabam funcionando, portanto, não só como manuais de sobrevivência na selva literal, mas também como manuais de life coaching, livros de autoajuda ou palestras motivacionais, orientadas por um conhecido discurso corporativo segundo o qual é preciso suportar a pressão sem perder a capacidade produtiva. É nesse sentido que podemos concordar quando Feldman (2008) argumenta que os reality shows de confinamento, mas, para nós, também os de sobrevivência - promovem uma espécie de pedagogia social no âmbito audiovisual voltada para o compartilhamento de modelos de gestão de si ancorados na resistência ao sofrimento e aos reveses, mas não de qualquer forma. Para gozar da legitimidade do sobrevivente em nossos tempos, é preciso ser resiliente e também competitivo, persistente, colaborativo, aguerrido, estratégico, político, entre outras tantas qualidades esperadas do sujeito empreendedor de si.

\section{A racionalidade do "sobrevivencialismo"}

Em Largados e Pelados, ao final de cada episódio, os participantes recebem uma nota, intitulada Primitive Survival Rating (PSR ou, em português, Avaliação de Sobrevivência Primitiva), formulada pela produção com base no desempenho ao longo do desafio. Aqueles participantes que obtiveram os melhores resultados, os que melhor suportaram, recebem notas mais altas. Todos os que participam e completam o desafio dos 21 dias têm sua PSR aumentada - conforme a figura 7 -, mesmo que minimamente, exceto os desistentes e os que dependeram demais de seus parceiros sem oferecer muito em troca.

Figura 7 - Frame do primeiro episódio da quinta temporada de Largados e Pelados. Avaliação de Sobrevivência Primitiva da participante Kim Kelly.

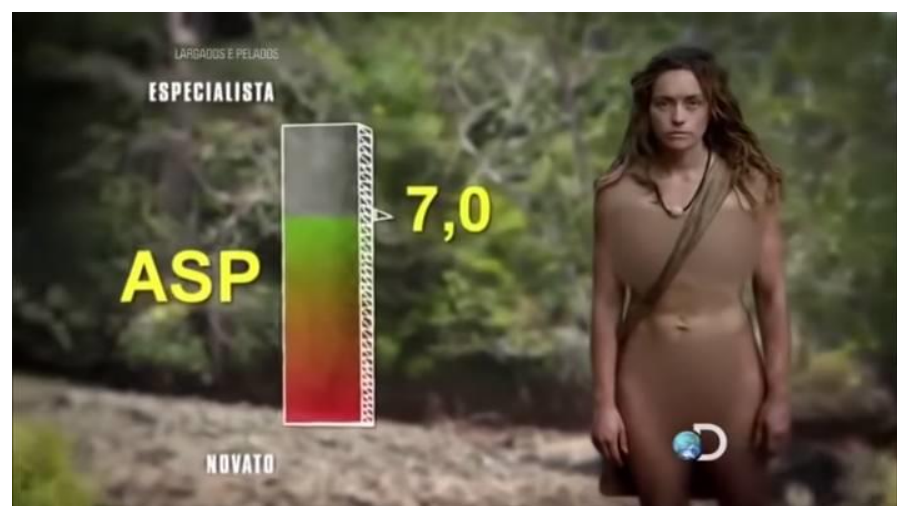

Fonte: FORSAKEN (2015). 
Para além do conceito de darwinismo social que permeia certa crítica a esses programas como produtos do mais genuíno espírito meritocrático capitalista (MURRAY, 2001), esses mecanismos avaliativos, discursos pedagógicos e parâmetros morais em torno dos sobreviventes insinuam um tipo de racionalidade criadora de um conjunto amplo de referências valorativas relacionadas ao sofrimento heroico, mas, sobretudo, ao governo de si, ao sujeito empreendedor de si, que assume a responsabilidade de enfrentar os riscos e o sofrimento por conta própria e voluntariamente.

Conforme argumentamos anteriormente (LAGE, 2018), o elogio à sobrevivência associada ao sofrimento redentor, a certos parâmetros morais e ao imperativo da fala constituem um esquema no qual a própria vida, sob a forma da sobrevida, da vida sobrevivente, foi transformada em força produtiva. Nesse sentido, a capacidade mesma da vida em se manter viva se tornou objeto das técnicas e dos cálculos de poder. Temos, assim, duas importantes chaves compreensivas dessas produções televisivas, ambas de inspiração foucaultiana. Em primeiro lugar, a que recoloca os reality shows de sobrevivência na condição de dispositivos que definem uma ordem moral segundo relações de poder "que se apoiam em formas de saber calculados e racionais, e que são acompanhados de técnicas de direcionar e regular o comportamento" (LEMKE, 2017, p. 24). Em segundo lugar, ainda é preciso argumentarmos que esses enredos de aventura tecidos pelos reality shows de sobrevivência são, também, verdadeiras cartilhas de empreendedorismo inspiradas em

[...] práticas moleculares de distribuição de méritos e deméritos, na produção da dependência e do assujeitamento, mesmo quando dependência e assujeitamento se fazem, como no caso do "empresário de si mesmo", pela ativação e mobilização da iniciativa e da liberdade - ou potência de agir - do indivíduo. (LAZZARATO, 2011, p. 85).

Assim, é subjacente à inversão histórica do conteúdo moral da sobrevivência a compreensão de que, em seu avatar apresentado pelas produções televisivas, a figura do sobrevivente é conjugada a uma racionalidade ancorada na produção de saberes, nas relações de poder e em técnicas de si. Logo, mais do que pensar o sobrevivente como efeito apenas de seu assujeitamento às lógicas pedagógicas, é preciso levar a sério a afirmação de Foucault (2006) de que o essencial no adestramento dos indivíduos não é negativo. Podemos dizer, então, que a ratio sobrevivente ensinada pelos reality shows é positiva, no sentido de que produz indivíduos, estimula suas capacidades, orienta seu campo de ação, 
apresenta-lhes técnicas de si que lhes permitem efetuar "certo número de operações sobre seus corpos e suas almas, seus pensamentos, suas condutas, seus modos de ser; de transformarem-se a fim de atender um certo estado de felicidade, de pureza, de sabedoria, de perfeição ou de imortalidade" (FOUCAULT, 1994, p. 785, tradução nossa).

O cálculo das notas dos desafiantes, isto é, de seu desempenho frente a um campo de possibilidades funciona como metáfora do saber relacional necessário à reprodução das relações de poder como "condução de condutas". Assim, a pedagogia desses reality shows opera delimitando "[...] um conjunto de ações sobre ações possíveis" (FOUCAULT, 1995, p. 243), mas não pela via da coerção ou da interdição. Trata-se de uma forma de direção das condutas com base naquele saber relacional e racional sobre as melhores formas de agir frente aos desafios ("resistir sempre, desistir jamais"), as técnicas mais indicadas ("sobrevivência como equação") e as posturas recomendáveis ("ética do trabalho em grupo"). Desse modo, o sobrevivente é aquele que passa pelo sofrimento e dele tira alguma lição. 0 mérito, o heroísmo do sobrevivente é ter corrido o risco, ter superado as adversidades. Sua vitória é sobre si mesmo, suas fraquezas, medos, emoções.

A essas lições sobre como ser um sobrevivente heroico acrescenta-se uma pedagogia do bom sofredor como aquele que não tem vergonha de expor o sofrimento. Como demarca Didi-Huberman (2016), somos culturalmente condicionados a conter certas emoções quando elas vêm à tona, especialmente em público, diante dos olhares e julgamentos de outrem. "Aquele que se emociona diante dos outros [...] expõe sua fraqueza, ele expõe seu não poder [impouvoir], ou sua impotência, ou sua impossibilidade de 'encarar', de 'manter as aparências"' (DIDI-HUBERMAN, 2016, p. 19). A nosso ver, a inversão moral da figura do sobrevivente também converte essa demonstração de fraqueza em evidência de força. Programas como Largados e Pelados nos mostram, a cada capítulo em que seus desafiantes padecem e superam suas provações, que faz parte de ser bom sofredor não conter mais as emoções. Não há mais do que ter vergonha. Redentor, o sofrimento é bem-vindo, mas apenas se vier acompanhado de dor e de superação.

No caso dos reality shows de sobrevivência, a voluntariedade e a obstinação em seguir as regras do jogo demonstram uma profunda penetração dessas relações de poder nas esferas da ação e da produção da subjetividade. Nessas produções televisuais, "[...] as cobaias sabem que o são e agem de acordo" (VIANA, 2012, p. 39). Na outra ponta dessas relações de poder, a figura do sobrevivente, outrora condenada pelo dilema moral de ter 
sobrevivido à custa de outros e marcada por situações de injustiça, violência e vulnerabilidade, passa a ser exaltada por atributos pessoais, por habilidades e competências individuais, pelo "mérito" de se prestar a sofrer, fazê-lo diante das câmeras e permanecer vivo para contar o que viveu e as lições edificantes que aprendeu: "Quando eu penso na experiência, eu acho que há um nível de empoderamento que é inédito pra mim. Eu posso dizer pra mim mesma: eu fiz isso. No final, eu sou capaz de muita coisa!", exclama a desafiante Dani Julien, ao final do terceiro capítulo da terceira temporada de Largados $e$ Pelados.

É a partir de uma compreensão positiva das relações de poder que Foucault relaciona as tecnologias de dominação com as técnicas de si, ou mesmo com o governo de si. A delimitação do campo de ações e condutas acontece por meio do exercício da própria liberdade de agir, orientada de acordo com o que se aprende a respeito dos campos de ação. Podemos dizer, então, que, nessa conjugação entre saberes, poderes e técnicas de si operada pelos programas televisivos, as técnicas primitivas de sobrevivência vêm acompanhadas de lições decisivas sobre equilíbrio emocional, persistência, foco, pensamento positivo, empoderamento feminino (e também afirmações de masculinidades) e outras tantas linhas de ação e modelos de postura vendidos pelos livros de empreendedorismo e/ou autoajuda. Nessa síntese de relações de saber e poder, surge um modelo, um manual de sobrevivência, tecido pela didática do sofrimento televisionado.

Para entendermos essa teia conceitual em termos práticos e mesmo empíricos, basta pensarmos que o "treinamento" ofertado pelos reality shows de sobrevivência ocupa o lugar daquilo que Foucault $(2006 ; 2015)$ chamou de poder pastoral, um tipo de relação de poder benfazejo, isto é, voltado para o bem daqueles que estão sob seus cuidados. A diferença é que, em vez da salvação extramundana oferecida pela autoridade pastoral por meio das normas morais que regem o "governo das almas", como diria Lemke (2017, p. 18), pela via da direção de consciência, estamos diante de um tipo de relação de poder que se desenha como "imanência da produtividade", nas palavras de Pogrebinschi (2004, p. 199), que age diretamente sobre a consciência dos indivíduos, sem forçá-los a se examinar, mas a reagir. Não há salvação, tampouco cura. A racionalidade sobrevivente dos reality shows é a lógica empresarial e de mercado. 0 que esses programas nos ensinam? Certamente, não apenas a sobreviver numa floresta remota, sem água nem alimento. São narrativas que se ocupam de 
ilustrar um tipo de conduta empresarial dos indivíduos como empreendedores de si mesmos. Quem sobrevive à selva certamente sobreviverá à vida urbana contemporânea.

Além de não haver "vencedor", também não há contrapartida financeira nem prêmios milionários. 0 que os participantes dizem buscar ao investirem nesses reality shows é não apenas o reconhecimento público, mas um improvement, uma espécie de ascensão de si próprio. No caso de Largados e Pelados, os desafiantes evocam com frequência, nos episódios, justificativas para se colocarem naquelas circunstâncias: o desejo de dar uma lição de vida para os filhos, a expectativa de conhecer os próprios limites, a busca por uma experiência radicalmente diferente. Nessa lógica, o sofrimento vivido pelos participantes nunca é fortuito. Como assinala Foucault (2008), o indivíduo produzido pelo neoliberalismo opera segundo investimentos e recompensas. Trata-se de um plano permanente de aperfeiçoamento e de autorrealização, que implica custos e sacrifícios como esforços justificáveis na direção do sucesso pessoal.

\section{0 assujeitamento e a "vida capaz de condutas"}

Seriam, então, os participantes desses programas e os próprios espectadores apenas marionetes de uma cultura capitalista do risco, da resistência e da sobrevivência, marcada pelo espetáculo do sofrimento, pelos modelos vitimários, pelo elogio da resiliência e pela capilaridade das relações de poder na promoção racional do aprimoramento produtivo de si? A essa indagação, podemos acrescentar outra: como resistir quando a própria resistência é objeto por excelência dos mecanismos e cálculos do poder?

Em sua cartografia avessa ao niilismo, Pelbart (2016) encontra uma espécie de linha de fuga oferecida pelo próprio esquema conceitual foucaultiano, a partir da qual é preciso entender que "[...] a vida sobre a qual as técnicas de si incidem é sobretudo uma vida capaz de condutas, uma vida suscetível de adotar diversas direções" (PELBART, 2016, p. 259). É, portanto, necessário pensar a partir dos dispositivos de governamentalidade, que fomentam práticas de gestão de si com base no pressuposto da vida capaz de condutas. As desistências dos participantes de Largados e Pelados são ilustrativas se quisermos aplicar esse raciocínio à lógica dos reality shows de sobrevivência. Não exatamente quando ocorrem segundo o enredo do programa, por estafa, doença, acidente ou fragilidade emocional, pois, nesses casos, elas até reforçam o discurso de que o desafio, como o próprio mercado de trabalho, não é para qualquer um. Porém, em raros episódios, as desistências são decisões tomadas 
sem maiores justificativas, tão somente porque os participantes já não se prestam mais a fazer parte nem mesmo da encenação do próprio fracasso.

Há ocasiões em que os produtores aparecem tentando demover os participantes da ideia de deixar o desafio, como no segundo episódio da sétima temporada, exibida em 2017. Mesmo no 15ำ dia do desafio de sobreviver na Amazônia equatoriana, o atleta Wes Adams pede para "deixar o jogo". Em um dado momento, ele caminha na direção contrária da equipe de filmagem, que o segue persistentemente, conforme a figura 8. 0 participante se desculpa com a parceira de desafio, resiste às investidas do produtor do programa, como se nota na figura 9, e pergunta em qual direção deve ir para sair dali.

Figura 8 - Frame do segundo episódio da sétima temporada de Largados e Pelados. Wes Adams dá as costas para a produção do programa.

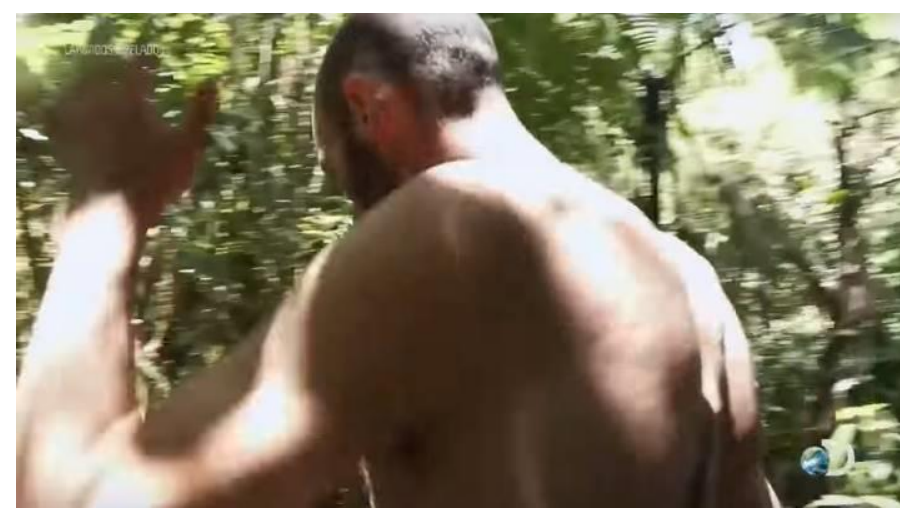

Fonte: WASHED OUT (2017).

Figura 9 - Frame do segundo episódio da sétima temporada de Largados e Pelados. Produtor do programa questiona Wes Adams sobre abandono do desafio.

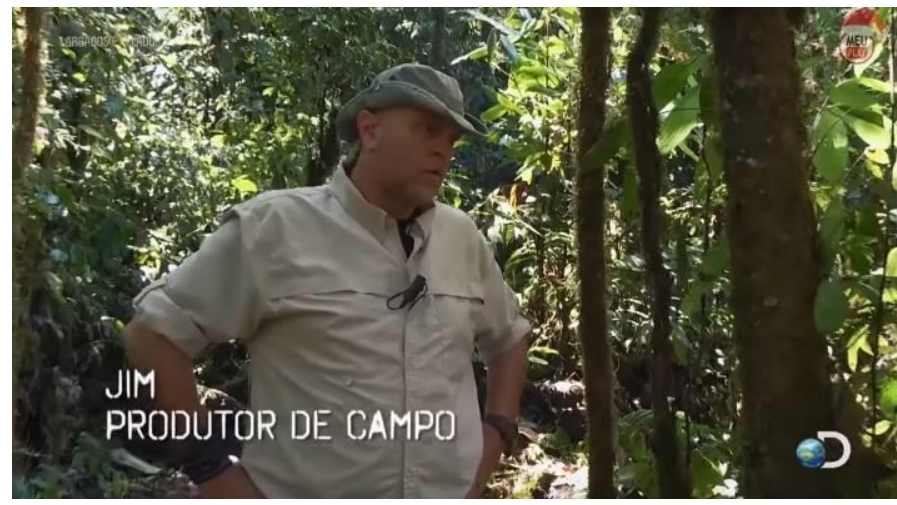

Fonte: WASHED OUT (2017). 
Para Pelbart (2007), o mesmo corpo que funciona como vetor de resistência quando prospera na dificuldade é o corpo que resiste à lógica do biopoder quando para de funcionar regularmente. Curiosamente, é a vida reduzida ao corpo biológico que dá os sinais vitais de alerta. É quando o corpo se recusa a tornar-se herói e se ocupa de tentar viver, e não mais sobreviver. "Em suma, num sentido muito amplo, o que o corpo não aguenta mais é a mortificação sobrevivencialista" (PELBART, 2007, p. 62). Se o corpo não aguenta mais, se denuncia a pressão excessiva por meio dos sinais vitais, se interrompe o sofrimento com um desmaio, é porque é ele quem opera como vetor de resistência. A última palavra é do corpo. Eles podem até querer continuar a experiência, manter-se firmes no papel de cobaias, obstinados na tentativa de vencer o sofrimento, mas é o corpo, em sua vulnerabilidade, que reage e falha, perfurando a regulação e a roteirização dessas produções televisivas.

\section{Na distância da vítima: considerações finais}

Apesar da inversão histórica do estatuto moral do sobrevivente que os programas televisivos de sobrevivência parecem apresentar, ainda há uma dimensão moralmente ambígua e mesmo contraditória na definição do modo "sobrevivente" de ser como modelo contemporâneo de produção da subjetividade. Isso porque a face oposta dessa figura não é apenas a da vítima inerte, mas a da morte. Não há, nos dicionários, um antônimo para o termo sobrevivente. Há apenas para o verbo sobreviver: morrer, perecer, sucumbir. Como ressalta Orgad (2009), a “[...] constituição do sobrevivente como papel legítimo e desejável depende e, por sua vez, reproduz o rechaço à morte e ao morrer" (ORGAD, 2009, p. 155, tradução nossa). Ou seja, a promoção da sobrevivência é, necessariamente, a eliminação da morte e do próprio sofrimento do horizonte de possibilidades. As relações de poder que organizam dispositivos e fomentam técnicas para o cuidado de si são, essencialmente, poderes sobre a vida, cujo objetivo é fazer viver, regulando modos de agir e pensar, modulando as formas de ser.

De maneira mais geral, o que se observa, a partir dessas narrativas e dos parâmetros morais que elas instituem, parece ilustrar o sintoma de uma transformação gradativa dos dispositivos e instituições que regulam a vida, a morte e o cuidado (MEMMI; TAÏEB, 2009). Revestidas de uma didática televisionada, essas pedagogias do autocuidado e do autoaprimoramento assumem o lugar tradicional do Estado de bem-estar, ou mesmo das instituições de vigilância e prevenção. 0 cuidado com a saúde, com o corpo, com a vida e, por 
certo, com as próprias capacidades e aptidões produtivas é como que delegado aos próprios indivíduos por meio desses novos agentes, experts e coachs de toda ordem, e repetido à exaustão sob a forma de novas práticas, "sobrevivencialistas". Se, por um lado, isso poderia sugerir um acréscimo à autonomia do indivíduo, livre para investir em si próprio, na verdade indica apenas um reforço da lógica de controle social travestida pelo discurso meritocrático de que "os melhores sobrevivem" e pela reafirmação de formas de saber.

Ao instituírem um regime estético e uma gramática moral centrados no corpo do sobrevivente, ou do desistente, esses programas também passam a depender do corpo. De um lado, precisam submetê-lo à roteirização, ao registro permanente pela equipe de filmagem e ao enredo de sofrimento e redenção da narrativa heroica e de aventura. De outro, devem liberá-lo para agir conforme seu próprio arbítrio, mas dentro de um horizonte circunscrito de linhas de ação. É por isso que os reality shows de sobrevivência, ao que parece, não são causas, mas, sim, efeitos e dispositivos agenciadores de uma racionalidade ordenadora de saberes e poderes direcionados ao imperativo de aprimoramento da capacidade produtiva dos sujeitos e de superação da vergonha subjacente ao sofrimento.

Esse modelo da figura do sobrevivente televisivo, embora remeta às ideias de comunhão de sofredores, de desafio a ser transposto, de luta persistente e, por fim, de política como formação de alianças estratégicas, converte-as todas em mecanismos próprios da dimensão econômica dos vínculos. Não há, exatamente, um sobrevivente que "resta" da experiência, como diria Agamben (2008) à luz da figura do mártir. 0 que há, na prática, são sobreviventes "produzidos" voluntariamente pela própria experiência, com habilidades físicas e mentais que o tornam capaz de cuidar de si, de sua equipe e de perseverar mesmo diante da escassez de recursos. Ora, essa é a própria conduta dos makers, dos empreendedores, dos profissionais multitarefa, dos vendedores, dos trainees, dos managers: fazer mais, de modo criativo, com cada vez menos e diante das adversidades. A vítima tem sua satisfação, sua redenção e se torna figura moralmente desejável desde que se produza no avesso da vítima.

Orgad (2009) chama atenção para as implicações morais e éticas desse elogio complacente à sobrevivência: o perigo, diz a autora, é que "privilegiar o sobrevivente pode menosprezar o compromisso de atender e alocar recursos para traumas e sofrimentos generalizados que não produzem 'sobreviventes'. Uma cultura democrática não deve permitir apenas os discursos de que os 'mais aptos' sobrevivem" (ORGAD, 2009, p. 156, 
tradução nossa). Nos programas televisivos que investigamos, tomando como exemplo o top rated Largados e Pelados, o sobrevivente se produz na distância da vítima, do desistente, do incapaz, do frágil. Oferece-se como lugar moralmente desejável e legítimo. Constrói-se um sobrevivente heroico, ainda que sem realizar nenhum ato heroico. E a própria televisão atua como dispositivo disciplinar, mas, sobretudo, pedagógico, criando em seus enredos um modelo vitimário desfavorável a qualquer outra experiência que não seja a do sofrimento redentor, a da resistência heroica e a do aprimoramento de si a qualquer custo.

\section{Referências}

AGAMBEN, G. 0 que resta de Auschwitz: o arquivo e a testemunha. São Paulo: Boitempo, 2008.

BRUCKNER, P. A tentação da inocência. Lisboa: Publicações Europa-América, 1996.

DIDI-HUBERMAN, G. Que emoção! Que emoção? São Paulo: Editora 34, 2016.

FELDMAN, I. Reality show: um dispositivo biopolítico. Cinética, p. 1-30, 2008.

FISCHER, R. M. B. Uma análise foucaultiana da TV: das estratégias de subjetivação na cultura. Currículo sem fronteiras, v. 2, n. 1, p. 41-54, 2002.

FOUCAULT, M. Les techniques de soi. In: _. Dits et Écrits IV. Paris: Gallimard, 1994, p. 785813.

FOUCAULT, M. O sujeito e o poder. In: DREYFUS, Hubert L.; RABINOW, Paul. Michel Foucault - uma trajetória filosófica: para além do estruturalismo e da hermenêutica. Rio de Janeiro: Forense Universitária, 1995. p. 231-249.

FOUCAULT, M. Sexualidade e poder. In: FOUCAULT, M. Ditos e escritos, volume IV: Ética, sexualidade, política. Rio de Janeiro: Forense Universitária, 2006, p. 56-76.

FOUCAULT, M. Nascimento da Biopolítica: curso dado no Collège de France (1977-1978). São Paulo: Martins Fontes, 2008.

FOUCAULT, M. "Omnes et Singulatim": uma Crítica da Razão Política. In: FOUCAULT, M. Ditos e escritos, volume IV: estratégia, poder-saber. Rio de Janeiro: Forense Universitária, 2015.

FORSAKEN [Abandonada]. David Garfinkle; Jay Renfroe; Steve Rankin; Mathilde Bittner; Denise Contis; Joseph Boyle. Discovery Channel, 4 out. 2015. Programa televisivo. 
LAGE, L. R. A ética e a estética da sobrevivência na TV: sofrimento, resiliência e biopoder. In: HOLZBACH, Ariane; CASTELLANO, Mayka.. (Org.). TeleVisões: Reflexões para além da TV. 1ed.Rio de Janeiro: E-papers, 2018, v. 1, p. 131-152.

LAZZARATO, M. 0 governo das desigualdades: crítica da insegurança neoliberal. São Carlos: EdUFSCar, 2011.

LEMKE, T. Foucault, governamentalidade e crítica. São Paulo: Editora Filosófica Politeia, 2017.

MAN Vs. Amazon [Homem vs. Amazônia]. David Garfinkle; Jay Renfroe; Steve Rankin; Mathilde Bittner; Denise Contis; Joseph Boyle. Discovery Channel, 16 mar. 2014. Programa televisivo.

MEMMI, Dominique; TAÏEB, Emmanuel. Les recompositions du «faire mourir»: vers une biopolitique d'institution. Sociétés contemporaines, n. 3, p. 5-15, 2009.

MURRAY, K. Surviving Survivor: reading Mark Burnett's field guide and de-naturalizing social darwinism as entertainment. The Journal of American Culture, 24(3-4), p. 43-54, 2001.

NAYAR, P. Scar cultures: Media, spectacle, suffering. Journal of Creative Communications, v. 4, n. 3, p. 147-162, 2009.

ORGAD, S. The survivor in contemporary culture and public discourse: a genealogy. The Communication Review, v. 12, n. 2, p. 132-161, 2009.

PELBART, P. P. Biopolítica. Sala Preta, v. 7, p. 57-66, 2007.

PELBART, P. P. 0 avesso do niilismo: cartografias do esgotamento. São Paulo: n-1 edições, 2016.

POGREBINSCHI, Thamy. Foucault, para além do poder disciplinar e do biopoder. Lua Nova, São Paulo, n. 63, p. 179-201, 2004.

RECHTMAN, R.; FASSIN, D. L'empire du traumatisme: enquête sur la condition de victime. Paris: Flammarion, 2007.

SPECIAL: Double Jeopardy [Especial: Duplo perigo]. David Garfinkle; Jay Renfroe; Steve Rankin; Mathilde Bittner; Denise Contis; Joseph Boyle. Discovery Channel, 8 dez. 2013. Programa televisivo.

VAZ, P. R. G. Na distância do preconceituoso: narrativas de bullying por celebridades e a subjetividade contemporânea. Galáxia, n. 28, p. 32-44, dez. 2014.

VIANA, S. Rituais de sofrimento. São Paulo: Boitempo, 2012.

WASHED OUT [Abatido]. David Garfinkle; Jay Renfroe; Steve Rankin; Mathilde Bittner; Denise Contis; Joseph Boyle. Discovery Channel, 12 mar. 2017. Programa televisivo. 


\title{
Distant from victim: survival morality and the television production of entrepreneur of the self
}

\begin{abstract}
The article discuss, in survival reality shows, signs of a cultural and moral transformation of what is understood and legitimized as a victim, as sufferer and as survival in contemporary. From the analysis of the Discovery Channel's TV show Naked and Afraid, it is argued that these television productions invest narratively and aesthetically both in the spectacularization of suffering and in the cosmetic configuration of the survivor. Thus, the figure of the survivor becomes part of a pedagogy and rationality guided by a neoliberal logic of reconfiguration of self as enterprise. These reality shows therefore function as devices that produce modes of subjectivation associated with the prodigious and morally legitimate heroism of the survivor whose negative image is that of the victim unable to overcome misfortunes with resilience.
\end{abstract}

\section{Keywords}

Morality. Suffering. Survival. Television. Victim.

\section{Autoria para correspondência}

Leandro Rodrigues Lage

leandrolage@ufpa.br

\section{Como citar}

LAGE, Leandro Rodrigues; VAZ, Paulo Roberto Gibaldi. Na distância da vítima: moralidade sobrevivente e a produção televisiva do indivíduo empreendedor de si. Intexto, Porto Alegre, n. 52, e-104566, jan./dez. 2021. DOI: http://dx.doi.org/10.19132/1807-8583202152.104566

Recebido em 21/06/2020

Aceito em 09/09/2020

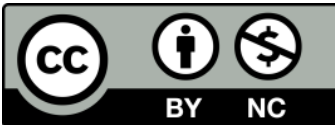

